\title{
Morphophysiological and yield attributes of groundnut varieties under different salinity stress conditions
}

\begin{abstract}
The study sought to evaluate the response of three groundnut genotypes (Binachinabadam-3, Dacca-1 and Zhingabadam) to various salt concentrations (D0 - Control, D1 - $2.5 \mathrm{dS} / \mathrm{m}, \mathrm{D} 2$ $5.0 \mathrm{dS} / \mathrm{m}, \mathrm{D} 3-7.5 \mathrm{dS} / \mathrm{m}, \mathrm{D} 4-10.0 \mathrm{dS} / \mathrm{m}, \mathrm{D} 5$ - $12.5 \mathrm{dS} / \mathrm{m})$ through observation of morphological and physiological characters. Based on relative performance of yield contributing characters and nutrient contents of leaves and stem, Binachinabadam-3 emerged to be a tolerant variety and based on root shoot characters, Dacca-1 appeared as tolerant while Zhingabadam always performed as sensitive variety. Salinity treatments had most adverse effects at flowering stage and followed the trend of sensitivity as flowering stage > vegetative stage > pre sowing stage > pod filling stage. All varieties were found to be tolerant up to salinity level of $7.5 \mathrm{dS} / \mathrm{m}$.
\end{abstract}

Keyword: Arachishypogaea; Oil crops; Salinity stress; Salinity tolerance 